\title{
Value Added Utilization of Petroleum Sludge Waste
}

\author{
Jianbing Li \\ Environmental Engineering Program, University of Northern British Columbia \\ 3333 University Way, Prince George, British Columbia, Canada V2N 4Z9 \\ Jianbing.Li@unbc.ca
}

\begin{abstract}
The treatment of petroleum sludge waste generated from oil and gas industry has received increasing concerns in recent years due to its hazardous nature. It is a complex emulsion of various petroleum hydrocarbons (PHCs), water, solid particles, and minerals. Given the stringent environmental regulations, there is a pressing need to develop cost-effective sludge treatment methods. In this presentation, the main methods used for petroleum sludge waste treament will be reviewed, and the value added utilization for oil recovery and environmental remediation will then be introduced. These include ultrasonic assisted solvent extraction, integrated solvent extraction and freeze/thaw, co-pyrolysis of petroleum sludge with forestry waste, and the utilization of sludge material as effective adsorbent development.
\end{abstract}

